\title{
Growth, Economic Instability and Popular Aspirations in South Asia: Some Leads for Public Policy
}

\author{
Siba Sankar Mohanty ${ }^{1 *}$ and Madhu Bisht ${ }^{2}$ \\ ${ }^{1}$ Department of Analytical and Applied Economics, Utkal University, Bhubaneswar, Odisha-751004, India \\ ${ }^{2}$ Department of Economics, School of Social Sciences, Doon University, Dehradun-248001, India \\ "Corresponding author: ssmoh_1976@yahoo.co.uk
}

\begin{abstract}
Global dynamics in the economic front have undergone several noteworthy changes in recent decades. At one hand, there is an increasing interest of the global finance capital in some prominent and emerging economies of South (emphasis ours). We see an increasing systemic resilience in these emerging economies towards shocks and economic fluctuations that have frequented the developed part of the globe more often than ever before. Many ascribe this resilience to an increasing recognition of the national governments of the Southern economies towards popular aspirations reflected in the manifestos of the ruling forces as well as formulation of pro-people policies than ever before. While this is something that needs attention, we also observe some contradictions of the growth process within the so called 'emerging south'. While the income of the nations is on the rise, the regional imbalances also are growing. At the same time, the deficit in some key development indicators such as health and education are also widening. Such a scenario is more so true in the context of countries of the South Asian region. Some flagship programmes and policies in the most South Asian countries clearly reflect the popular aspirations and development needs in these countries. The political forces in these countries have also become proactive in raising issues of development more prominently in their election campaigns and political literature. The present paper attempts to explain some such contradictions in the context of South Asia and based on the analysis of country specific data on income, health, education and other indicators from the global database of world development indicators (WDI) and with the help of vector auto-regression (VAR) method of analysis, the paper seeks to establish some linkages in these variables in the changing global scenario.
\end{abstract}

JEL Classification: D-72, E-62, F-02, H-53, I-18, I-28, N-15, N-35

Keywords: Global finance capital, Economic Growth, Human Development indicators, electoral policies, business cycles, economic stability, emerging economies, welfare programmes, fiscal policy

Global economy has undergone some significant changes, in the new millennium, in many forms. When it comes to opening up of economies, the share of trade in national income as represented by trade as per centage of GDP has gone up from around 40 per cent in early 1990s to more than 60 per cent in the year 2012. Here we clearly see two trend reversals; one in early 1990s when the share of trade in GDP in middle income countries surpassed the share in high income countries and two when in the beginning of the new millennium the share of trade in the low income countries also surpassed the share in the high income economies.
The developments in the new millennium have in fact established that the high income countries have become less open compared to the low and middle income countries (Fig. 1). We also notice a shift in interest of the global finance capital from developed world to some prominent economies of the South. As a share of domestic GDP, the net FDI inflows in low income countries have gone up from less than two per cent in 1999 to around 5 per cent in 2012, while in high income countries, the share have remained almost the same (Fig. 2). At the same time, we also notice a resilience in these emerging economies towards shocks and fluctuations in the 
business cycles that have frequented the globe more often than ever before.

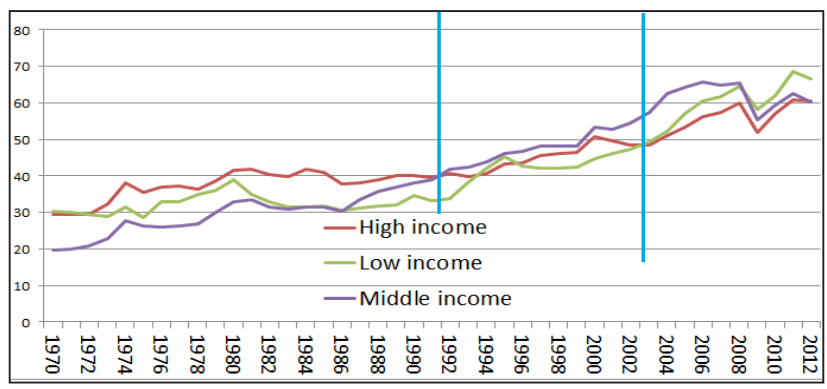

Fig. 1: Share of Trade in GDP (\%)

Source: World Development Indicators (WDI)

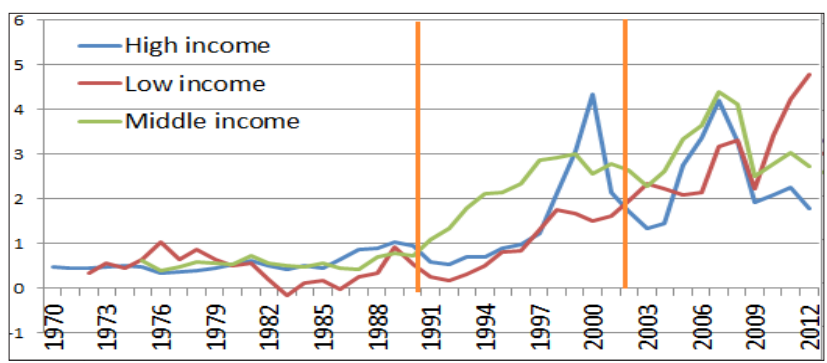

Fig. 2: Foreign direct investment, net inflows (\% of GDP)

Source: World Development Indicators (WDI)

As the available information suggests, the average annual growth rate of GDP has declined from 3.07 during 1970-1999 to 1.91 per cent in the new millennium in the high income countries. In low and middle income countries the average growth rate increased in the new millennium. The fluctuations in the growth rate as represented by the standard deviation of growth rates in both the phases also that there is a reversal in trend between both the phases, the latter being more unstable for the higher income countries (Table 1).

Table 1: Growth rates and fluctuations of GDP in low, middle and high income countries

\begin{tabular}{ccccc}
\hline & \multicolumn{2}{c}{$\begin{array}{c}\text { Average Annual } \\
\text { Growth Rate }\end{array}$} & $\begin{array}{c}\text { Standard Deviation } \\
\text { in Annual Growth } \\
\text { rate }\end{array}$ \\
\cline { 2 - 5 } Countries & $\mathbf{1 9 7 0 - 1 9 9 9}$ & $\mathbf{2 0 0 0 - 2 0 1 2}$ & $\mathbf{1 9 7 0 - 1 9 9 9}$ & $\mathbf{2 0 0 0 - 2 0 1 2}$ \\
\hline High income & 3.07 & 1.91 & 1.48 & 1.84 \\
Low income & 2.52 & 5.34 & 1.79 & 1.12 \\
$\begin{array}{c}\text { Middle } \\
\text { income }\end{array}$ & 4.35 & 5.89 & 1.48 & 1.76 \\
\hline
\end{tabular}

Source: Computed from World Development Indicators (WDI)

Many ascribe this resilience to an increasing recognition of the governments to the south towards popular aspirations reflected in the manifestos of the ruling forces as well as formulation of pro-people policies than ever before. But within the so called 'emerging south' we also observe some typical paradoxical contradictions. While the income of nations is on the rise, the regional imbalances also are growing. At the same time, the deficit in some key development indicators such as health and education are also widening. The countries of South Asia are no exception. In the last decade, we have witnessed some major policies in most South Asian Countries that clearly reflect the popular aspirations and development needs in these countries. The political forces in these countries have also become proactive in raising issues of development more prominently in their election manifestoes. But, there are issues in making provisions towards fulfilment of these aspirations; both at the level of making financial commitments as also in governance. The increased scope for government activities due to an expansion of the revenue base of the governments in these countries are also marred by the increased concessions and tax expenditures made by the governments in the name of promoting investment in these countries. The present paper attempts to explain some such contradictions in the context of South Asia and based on the analysis of country specific data on income, health, education and other indicators seeks to establish some linkages in these variables in the changing world economy. On the basis of statistical tools such as principal component analysis of selected variables and a model for vector auto regression we have tried to establish the linkages between variables representing macroeconomic structures, socioeconomic development and popular aspirations in eight South Asian countries.

\section{Review of Literature}

The available discourses on economic growth, stability and fluctuations have not only laid emphasis on macroeconomic variables as has been empirically studied by the mainstream, but also focus on different social and political factors playing a role in defining growth and fluctuations. What signifies the differences between countries in low, medium and high income groups is not just the per capita income, but also a socioeconomic and political structure or framework within the limits scope of 
which such income is generated and sustained over time. The available literature make attempts to exhibit such structural differences in many ways. Some try to generalise the relationships while some others seek to abstain from such generalisation.

Majid and Mahrizal (2007) suggest that variations in the economic growth rely very much on the evolution of economies and their own innovations. Growth promotion eventually happens through long run policies that may enhance the existing financial institutions in the banking sector as well as the stock market. Chaudhury (1991) on the basis of Granger-causality tests finds some sporadic links between defence expenditure and economic growth without making any attempt towards a prophetic generalisation. Ohanian (1991) on the basis of another study using vector auto-regression finds the relationship between national income and macroeconomic monetary variables such as interest rate, money stock and price level to be spurious. Balke (2000) on the basis of vector auto-regression analysis have suggested that output effect of shocks is larger in the "tight" credit regime and contractionary monetary shocks are more effective than expansionary shocks. Litterman (1986) developed a statistical forecasting model based on Bayesian vector auto regression to study the interplay of factors that affect growth and fluctuation in the macroeconomic coordination process. McCarty and Schmidt (1997) on the basis of a vector auto-regression Analysis of state-government expenditure on real and per capita welfare spending, on income output and subsequent tax proceeds, have found a high degree of responsiveness of the welfare spending on other forms of government expenditure, future tax proceeds and eventually the capacity of the government to intervene in the macroeconomic coordination processes.

The discourse on such relationships are diverse and within the limits of the scope of the present paper, it may not be possible to highlight most such literature available. The major concern in these studies, however is that, most of these studies is have chosen variables based on a very contextual and localised understanding of the variable interplay. Economies in which macroeconomic variables do play only a limited role is defining fluctuations, even not so well-defined variables play a major role.

\section{Method of Analysis}

For all practical purposes of this paper, the variables listed in Appendix Table 2 are clubbed into four sets. The first set represents the linkages with the external economy and other macroeconomic variables that may have a bearing on the growth of GDP in an economy and fluctuations thereof. Annexure Table 2 (a) lists these variables in the first set of variables indicated as ME.

The second set of variables are indicated as development indicators as identified by the UN Millennium campaign as targets for achieving Millennium Development Goals (MDGs). The

Table 2 (a): Macroeconomic variables possibly influencing fluctuations in GDP

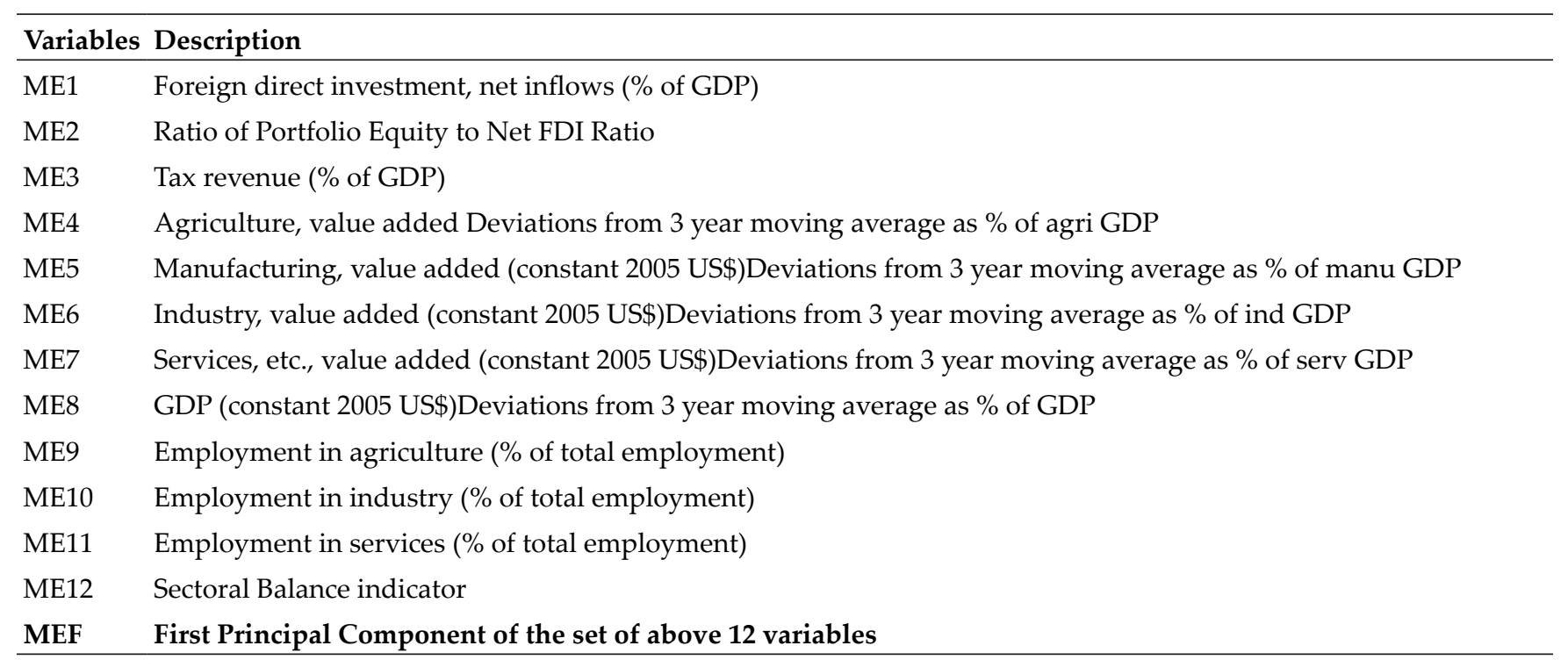


Table 2 (b): Millennium Development Goals (MDGs) related variables possibly influencing fluctuations in GDP

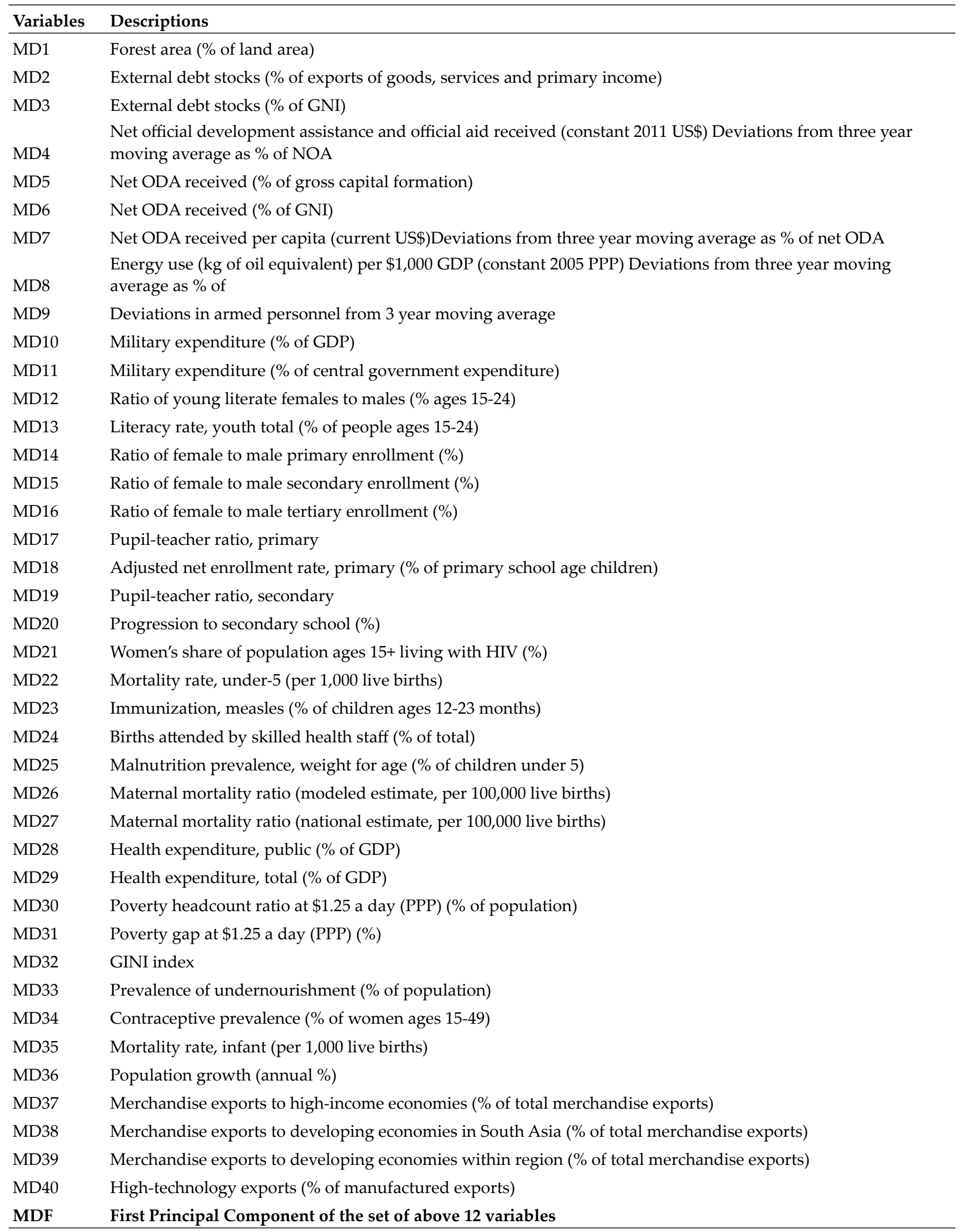


variable in the list is identified as MD. Annexure Table 2 (b) lists these variables in the first set of variables indicated as MD.

The third set of variables indicated as PA denotes the popular aspirations related to development in a country. While it is difficult to clearly identify and enumerate the variables represented by popular aspirations, we have compiled a set of 29 proxies related to issues identified as important in the manifestos of political parties in the last general elections in the respective countries or identified as issues of development in the plans, budget addresses and other documents. Annexure Table 2 (c) lists these variables in the first set of variables indicated as PA.

Principal component analysis method is adhered to enumerate the first principal component that represents the largest variability in the datasets in each of these three sets of information.

The fluctuation in growth process is measured by the absolute value of the deviations of per capita GDP from its three year moving average as \% of per capita GDP.

All the four composite variables used for a vector auto correlation (VAR) analysis are as under.

Table 2 (c): Popular Aspirations related variables possibly influencing fluctuations in GDP

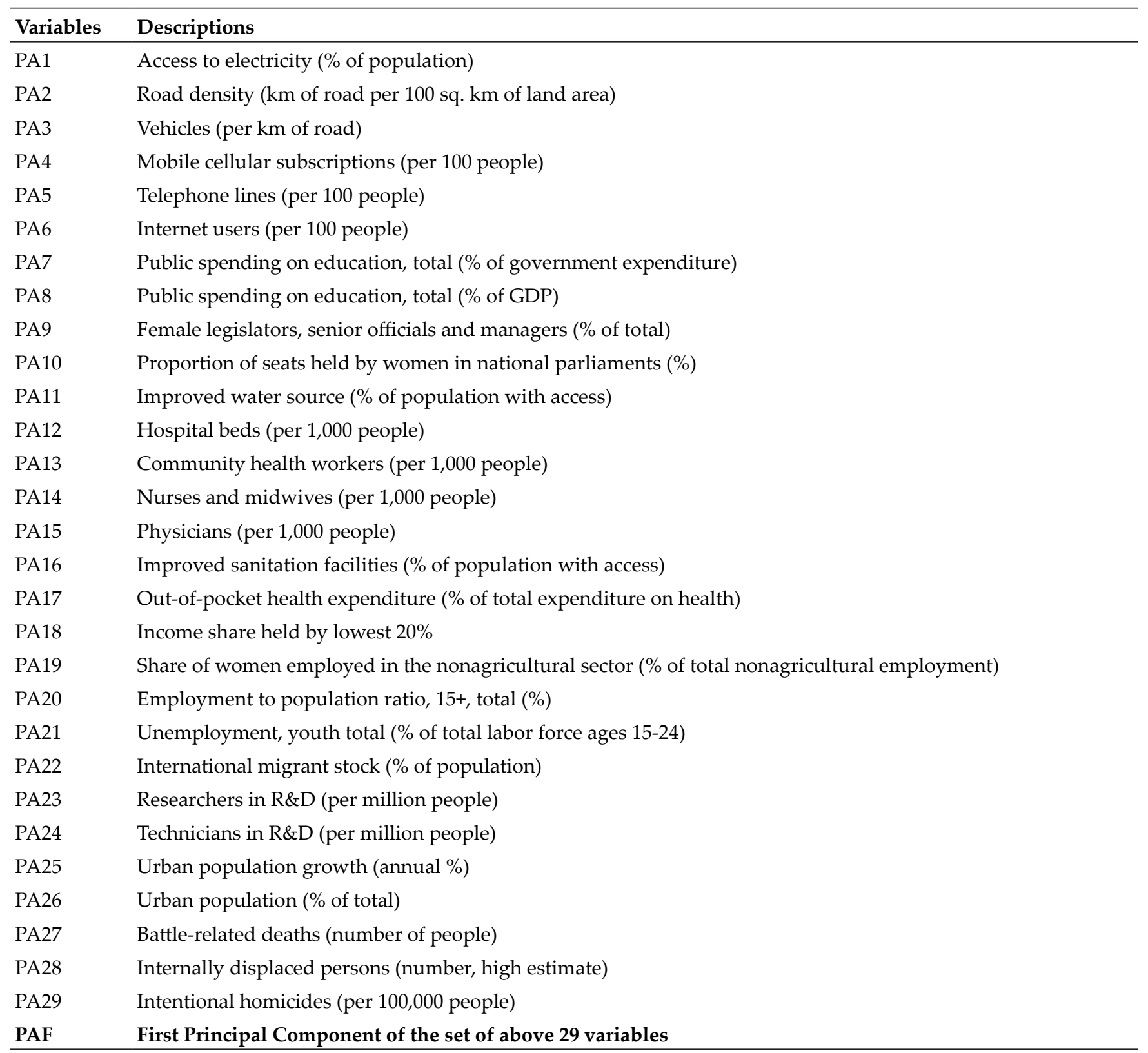


MEF (or E in equations) : first principal component of variables listed in Table 1(a) as macroeconomic variables.

MDF (or D in equations): First principal component of variables listed in Table 1(b) as developmental variables.

PAF (or A in equations): First principal component of variables listed in Table 1 (c ) as proxies of popular aspirations.

FLU (or F in equations): the variable computed as a representative of fluctuations.

The VAR model developed from the use of these variables with two lags may be written as;

$\mathrm{F}_{\mathrm{t}}=\alpha_{\mathrm{F}}+\mathrm{m}_{1} \mathrm{~F}_{\mathrm{t}-1}+\mathrm{m}_{2} \mathrm{~F}_{\mathrm{t}-2}+\mathrm{n}_{1} \mathrm{E}_{\mathrm{t}-1}+\mathrm{n}_{2} \mathrm{E}_{\mathrm{t}-2}+\mathrm{o}_{1} \mathrm{D}$

${ }_{\mathrm{t}-1}+\mathrm{o}_{2} \mathrm{D}_{\mathrm{t}-2}+\mathrm{p}_{1} \mathrm{~A}_{\mathrm{t}-1}+\mathrm{p}_{2} \mathrm{~A}_{\mathrm{t}-2}$

The criteria used for selection of lags is depicted in Table 3.

\section{RESULTS AND DISCUSSION}

The main results form country wise vector autoregression models present the following.
The time trend of fluctuations in GDP per capita show that the global economy has witnessed significant fluctuations in the deviations from their three year moving averages compared to South Asia. In most individual countries of South Asia the fluctuations in the GDP per capita are moderate in recent years. However, there are significant deviations across individual countries. While in countries like India, Nepal and Srilanka, the post 2000 years have witnessed significant levels of fluctuations, all other South Asian countries remained more or less stable in their per capita GDP growth rates in this period (Fig. 3). Even in India, Nepal and Sri Lanka the fluctuations had been in positive direction compared to the whole world. Further analysis on this is presented below.

In Afghanistan, the economy has improved significantly due to infusion of money through developmental grants and external aids in the post war phase since 2002. In Afghanistan, reconstruction efforts have made this country grow at a double digit rate in most of the years since 2002 due to several factors such as low base to compare,

Table 3: Selection of Lags

\begin{tabular}{ccccccc}
\hline Country & lags & loglik & $\mathrm{p}(\mathrm{LR})$ & $\mathrm{AIC}$ & $\mathrm{BIC}$ & $\mathrm{HQC}$ \\
1 & 1 & -145.016 & & $6.346756^{*}$ & $7.097235^{*}$ & $6.634472^{*}$ \\
1 & 2 & -130.79 & 0.0279 & 6.414981 & 7.765842 & 6.932869 \\
2 & 1 & -137.228 & & $6.047240^{*}$ & $6.797719^{*}$ & $6.334956^{*}$ \\
2 & 2 & -121.997 & 0.01574 & 6.076797 & 7.427658 & 6.594685 \\
3 & 1 & -237.941 & & 9.9208 & $10.671278^{*}$ & $10.208515^{*}$ \\
3 & 2 & -220.049 & 0.0031 & $9.848034^{*}$ & 11.1989 & 10.36592 \\
4 & 1 & -49.1758 & & 2.660608 & 3.411087 & 2.948324 \\
4 & 2 & -16.215 & 0 & $2.008268^{*}$ & $3.359129^{*}$ & $2.526156^{*}$ \\
5 & 1 & -270.178 & & $11.160702^{*}$ & $11.911181^{*}$ & $11.448418^{*}$ \\
5 & 2 & -257.708 & 0.07088 & 11.29646 & 12.64732 & 11.81435 \\
6 & 1 & -171.38 & & $7.360785^{*}$ & $8.111263^{*}$ & $7.648501^{*}$ \\
6 & 2 & -160.546 & 0.15418 & 7.559444 & 8.910305 & 8.077332 \\
7 & 1 & -118.332 & & $5.320443^{*}$ & $6.070922^{*}$ & $5.608159^{*}$ \\
7 & 2 & -111.596 & 0.63804 & 5.676765 & 7.027626 & 6.194653 \\
8 & 1 & -146.944 & & $6.420918^{*}$ & $7.171396^{*}$ & $6.708633^{*}$ \\
8 & 2 & -135.538 & 0.11885 & 6.597606 & 7.948467 & 7.115494 \\
9 & 1 & -132.479 & & $5.864583^{*}$ & $6.615061^{*}$ & $6.152298^{*}$ \\
9 & 2 & -121.515 & 0.1455 & 6.058256 & 7.409117 & 6.576145 \\
10 & 1 & -54.6795 & & 2.872287 & $3.622766^{*}$ & $3.160003^{*}$ \\
10 & 2 & -35.6713 & 0.00151 & $2.756590^{*}$ & 4.107451 & 3.274478 \\
\hline
\end{tabular}

Note: The asterisks indicate the best (that is, minimized) values of the respective information criteria, $A I C=A k a i k e$ criterion, $B I C=S c h w a r z$ Bayesian criterion and HQC = Hannan-Quinn criterion . 


\section{Afghanistan}

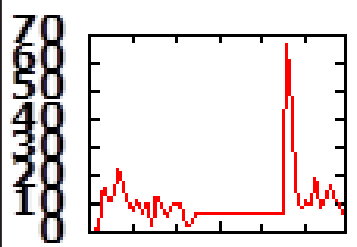

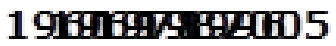

Maldives

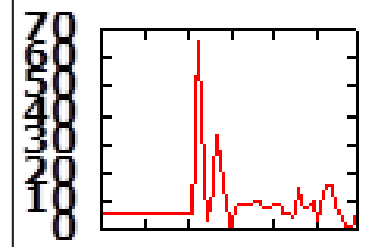

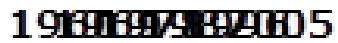

Bangladesh

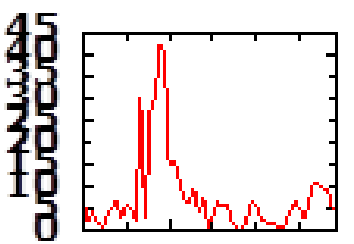

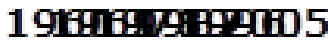

Nepal

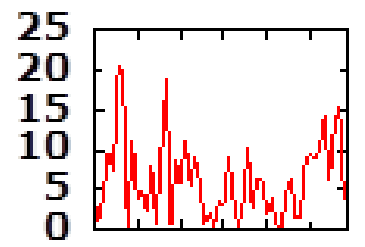

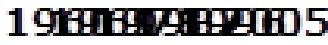

South Asia

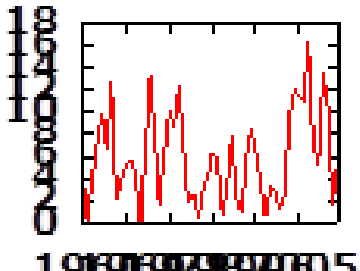

Bhutan

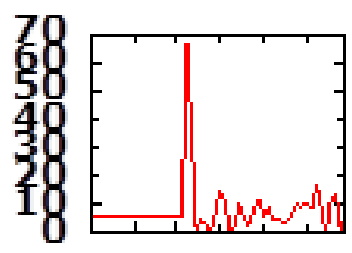

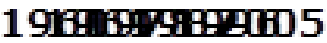

Pakistan

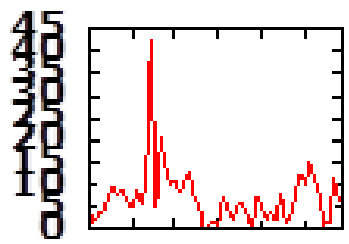

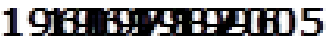

India

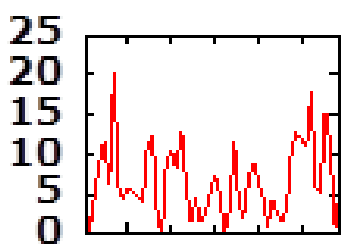

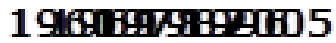

Sri Lanka

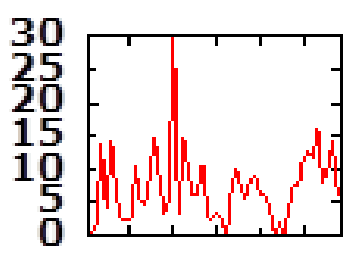

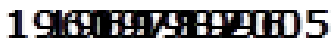

\section{World}
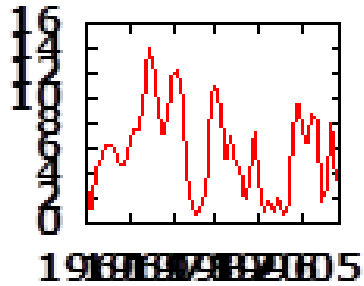

Fig. 3: Fluctuations in GDP per capita at constant prices in South Asian Countries

improved international cooperation leading to better macroeconomic performances vis-à-vis external sector, new avenues of trade that remained untapped in the war period and increased expenditure on developmental goals (MDGs) that might have contributed to the resilience of the economy in the post war phase (Takween and Mohanty, 2009).

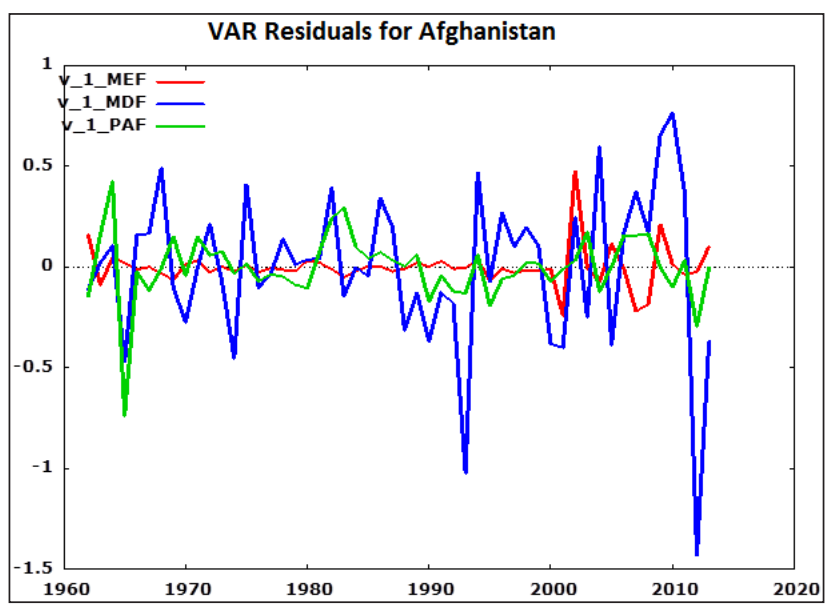

Fig. 4
Fig. 4 suggests that major variations have occurred in the first principal component representing developmental indicators in the last one decade. Given that the fluctuations in the growth rate have been moderate in this phase in Afghanistan, we may infer that interventions in developmental activities through variables as indicated in Table 2 (b) might have contributed to the resilience of the Afghan economy over the last decade. On the other hand, in Bangladesh, all the three sets of variables might have contributed to the resilience of the Bangladeshi economy. Such an understanding for Bangladesh has also been substantiated by Rahman (2009) with the view that although the effects of global economic fluctuations are well felt on the Bangladesh Economy too, the economy did not suffer much compared to the developed world for the basic reason that a highly globalised emerging economy (more than 9\% of GDP from exports and $85 \%$ of all exports destined for developed countries) like Bangladesh would benefit from a 
shift in the terms of trade in favour of cheaper Bangladeshi produce with the increase in distress in the developed world owing to economic crises. As has been cited by Rahman (2009), the quarterly growth rate of total exports destined for the US in Bangladesh grew from (-) 3.4 per cent in Q4 of 2007 to around 18 per cent in Q4 of 2008.

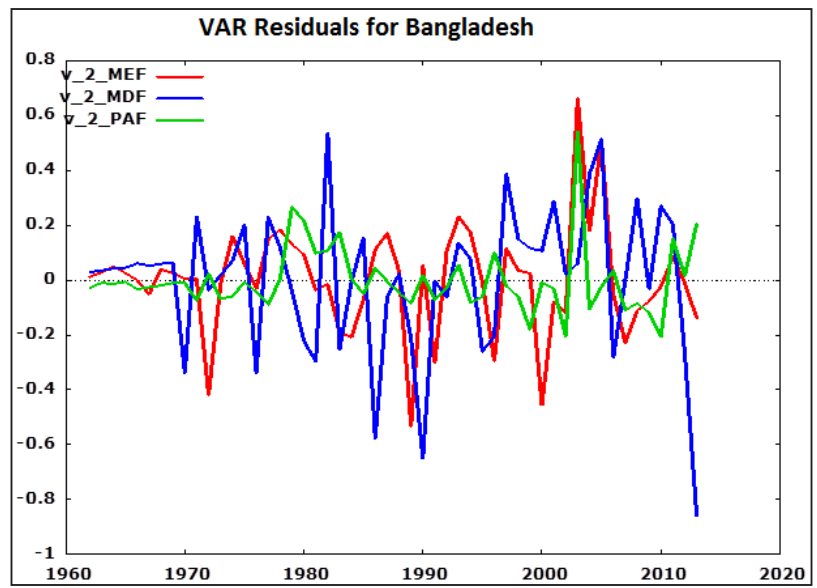

Fig. 5

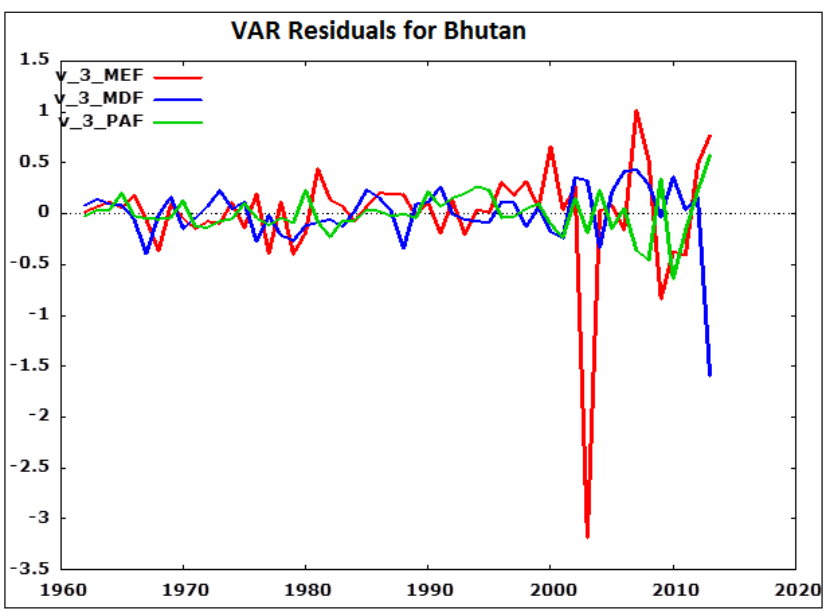

Fig. 6

In Bhutan and Nepal, all the three sets of variables played their role. In both the countries, the economic crisis in the global front did not have a significant impact because of sound macroeconomic management and lesser linkages with the global economy. The residual plots indicate that the resilience of these two economies both to the initial and longer term shocks may be contributed by all the three factors related to macroeconomic management, millennium development targets in public policies and the efforts towards restoration of variables linked with popular aspirations.
In Pakistan, Maldives and Srilanka too, given the political instability in all these countries, the resilience might have been caused due to the efforts related to developmental activities. But in India, the case is different. Here, the most prominent factor contributing to the economic resilience to fluctuations is probably the efforts towards upholding popular aspirations.

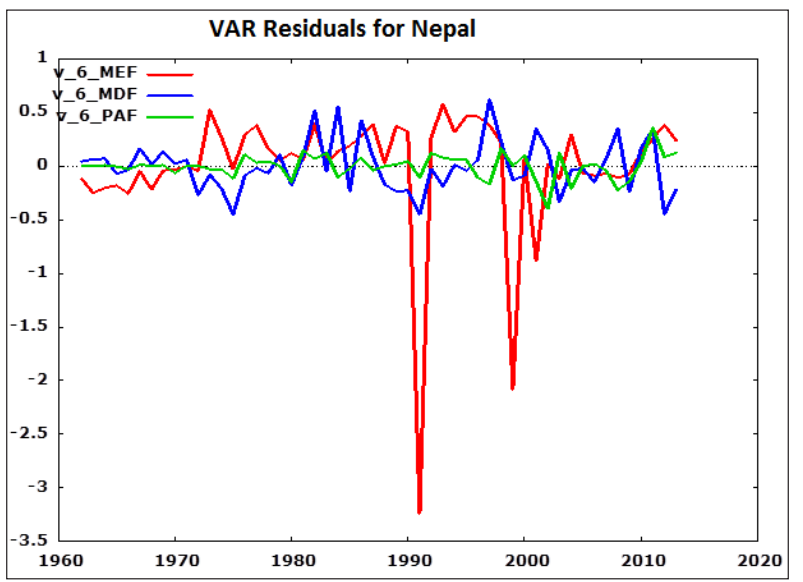

Fig. 7

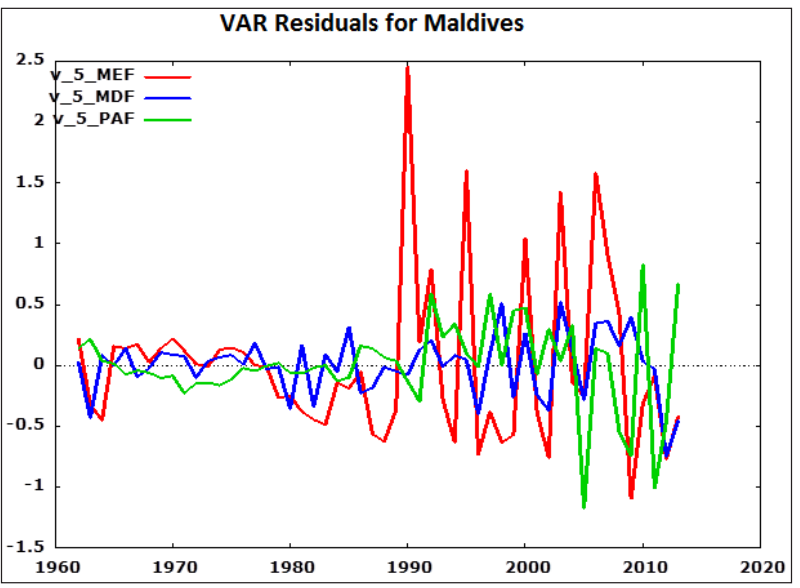

Fig. 8

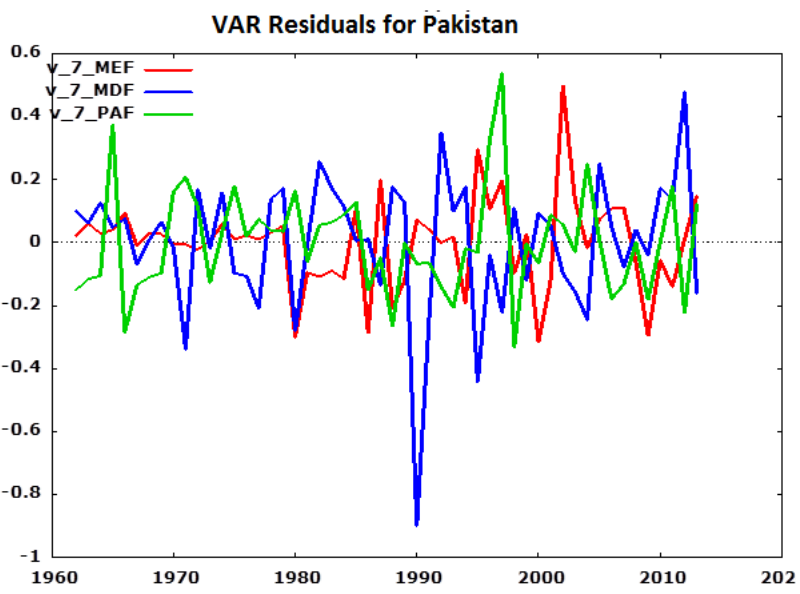

Fig. 9 


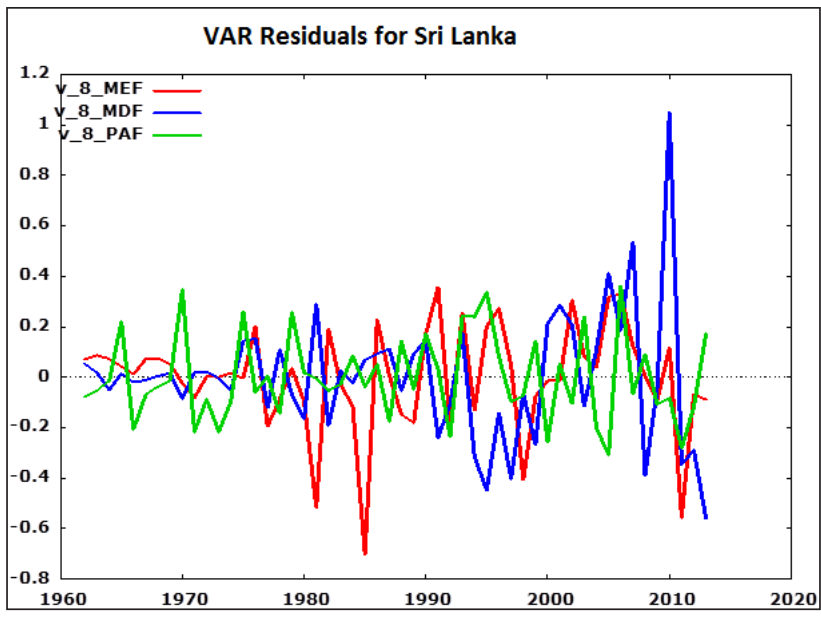

Fig. 10

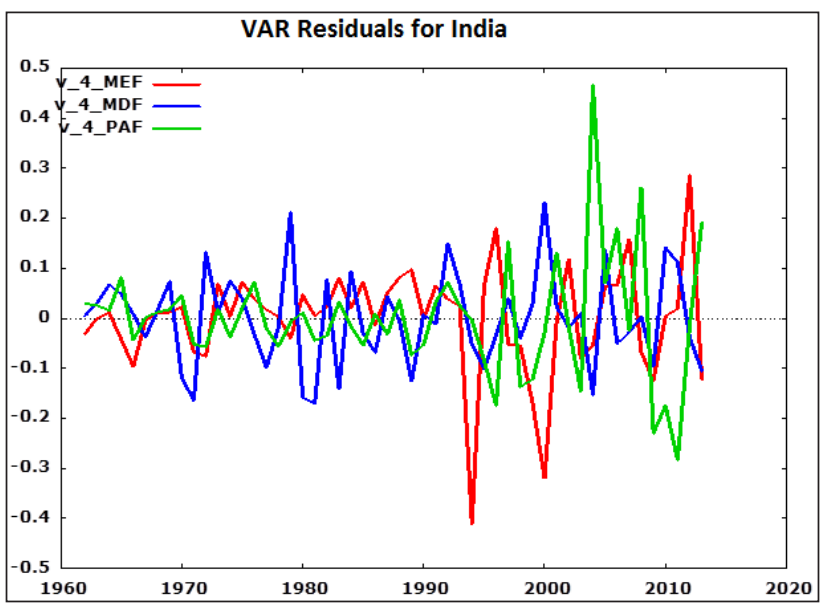

Fig. 11

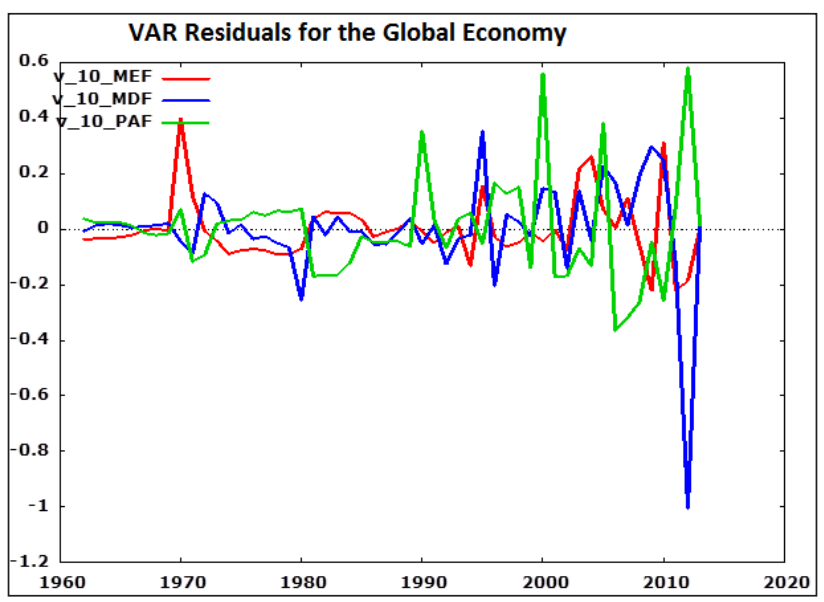

Fig. 12

\section{Concluding Notes}

We may conclude from the above analysis that while economic growth might have been a function of different macroeconomic variables, more so of variables related to the external economy in the post 2000 period, the fluctuations and shocks that retard the growth might be contributed by factors in the overall development framework set by the millennium development goals in the post 2000 phase and the efforts and conditions that shape the popular aspirations in an economy. The predominance of these factors might have helped the South Asian Countries to build a systemic resilience against global economic downturns and fluctuations that might have surfaced as the external realities.

\section{ACKNOWLEDGEMENTS}

This paper is a substantially revised version of the presentation made by the author in the Third Northern Regional Congress of the Indian Council of Social Science Research. The authors are thankful for the inputs provided by Prof. R. P. Mamgain, GIDR, Lucknow and Prof. V.K. Jain, JNU towards refining the ideas and working on the data.

\section{REFERENCES}

Balke, Nathan S. 2000. Credit and Economic Activity: Credit Regimes and Nonlinear Propagation of Shocks, The Review of Economics and Statistics, 82(2): 344-349 Published by: The MIT Press, URL: http://www.jstor.org/stable/2646828 .Accessed: 28/01/2015 04:52

Chowdhury, Abdur R. 1991. A Causal Analysis of Defense Spending and Economic Growth, The Journal of Conflict Resolution, 35(1): 80-97. URL: http://www.jstor.org/ stable/174205 .Accessed: 28/01/2015 04:51

Litterman, Robert B. 1986. A Statistical Approach to Economic Forecasting, Journal of Business \& Economic Statistics, 4(1): 1-4 URL: http://www.jstor.org/stable/1391378 .Accessed: 28/01/2015 04:48

Majid, M. Shabri Abd. and Mahrizal 2007. Does Financial Development Cause Economic Growth In The ASEAN Countries?, Savings and Development, 31(4): 369-398 Published by: Research Center on International Cooperation of the University of Bergamo URL: http:// www.jstor.org/stable/41406460 .Accessed: 28/01/2015 04:55

McCarty, Therese A. and Schmidt, Stephen J. 1997. A Vector-Auto-regression Analysis of State-Government Expenditure, The American Economic Review, 87(2). Papers and Proceedings of the Hundred and Fourth Annual Meeting of the American Economic Association (May, 1997), pp.278-282 Published by: American Economic Association Stable URL: http://www.jstor.org/ stable/2950931. Accessed: 28/01/2015 04:48 
Ohanian, Lee E. 1991. A Note on Spurious Inference in a Linearly Detrended Vector Autoregression, The Review of Economics and Statistics, 73(3): 568-571. URL: http://www. jstor.org/stable/2109588. Accessed: 28/01/2015 04:36

Bahman Hares Takween, Siba Sankar Mohanty 2009. Food for Thought: Analysis of Agriculture Financing in Afghanistan. Edited by Aunohita Mojumdar, Zarrena Vasquez, 06/2009; ActionAid Afghanistan.
Rahman, Mustafizur; Bhattacharya, Debapriya; Iqbal, Md Ashiq; Khan, Towfiqul Islam and Paul, Tapas Kumar. 2009. Global Financial Crisis Discussion Series: Paper 1Bangladesh, May 2009. Overseas Development Institute, 111 Westminster Bridge Road, London SE1 7JD. 